ISSN 0103-8478

\title{
Margem de segurança do meloxicam em cães: efeitos deletérios nas células sangüíneas e trato gastrintestinal
}

\author{
Margin of safety of meloxicam in dogs: deleterious effects on \\ blood cells and gastrointestinal tract \\ Marilac Maria Arnaldo Alencar ${ }^{1}$ Marília Taumaturgo Pinto ${ }^{2}$ \\ Diana Magalhães Oliveira ${ }^{3}$ Adriana Wanderley de Pinho \\ Pessoa $^{4}$ Ivanilde Andrade Cândido $^{5}$ Camila Gomes Virgínio ${ }^{6}$ \\ Henrique de Souza Matos Coelho ${ }^{6}$ Marcos Fábio Gadelha Rocha ${ }^{7}$
}

\section{RESUMO}

Este trabalho investigou a margem de segurança do inibidor COX-2, meloxicam, em cães, enfocando seus efeitos deletérios nas células sangüineas e no trato gastrintestinal. Para tanto, após uma avaliação clínico-laboratorial, os cães foram distribuidos nos seguintes grupos: I (placebo; $n=3$ ), II (piroxicam; $1,0 \mathrm{mg} \mathrm{kg}^{-1} ; n=5$ ), III (meloxicam; $0,2 \mathrm{mg} \mathrm{kg}^{-1} ; n=5$ ), IV (meloxicam; 1,0mg kg-1; $n=5$ ) e V (meloxicam; 2, $0 m g \mathrm{~kg}^{-1}$; $n=5)$. Os fármacos foram usados, por via oral, por 16 dias. No 170 dia, repetiu-se o hemograma completo e, então, procedeuse a eutanásia seguida pela necrópsia. No grupo I, não houve alterações dignas de nota. No grupo II, todos os cães apresentaram episódios moderados de vômito e diarréia. $O$ perfil celular sangüineo não foi significativamente modificado. Em dois cães, houve redução no hematócrito e na hemoglobina. $\mathrm{Na}$ necropsia, observaram-se focos hemorrágicos e lesões gastriduodenais moderadas. A análise microscópica revelou a presença de gastrite e enterite ulcerativa. No grupo III, quatro cães (80\%) apresentaram vômito e diarréia, sem alteração no perfil celular sangüineo. Na análise macroscópica, observaramse lesões brandas na mucosa gástrica e focos hemorrágicos no duodeno em quatro cães. Na histopatologia, observaram-se lesões sugestivas de discreta gastroenterite. No grupo $I V$, os cinco cães tiveram vômito e diarréia sanguinolenta. Quatro deles (80\%) apresentaram anemia ( $p \leq 0,05)$. Quatro e cinco cães apresentaram redução no hematócrito e hemoglobina, respectivamente. Ocorreram, ainda, leucocitose, neutrofilia e linfopenia significantes ( $p \leq 0,05$ ), em $60 \%$ dos cães. $\mathrm{Na}$ necrópsia, evidenciaram-se hiperemia, hemorragia e úlceras gástricas severas em $100 \%$ dos animais. Verificou-se na microscopia um quadro de gastroenterite ulcerativa nos cinco cães. No grupo $V$, todos os cães apresentaram sérios episódios de vômito, diarréia e melena. Os quatro (80\%) cães que suportaram o tratamento apresentaram anemia e leucocitose com neutrofilia e linfopenia significativas $(p \leq 0,05)$. Houve, ainda, uma redução no hematócrito e hemoglobina desses cães. Na necropsia, foram visualizadas hemorragias e graves ulcerações gastroduodenais. À histopatologia, evidenciou-se severa gastroenterite. Conclui-se que o meloxicam, mesmo sendo COX-2 seletivo, induz efeitos deletérios no trato gastrintestinal e células sangüineas de cães, quando administrado em concentrações cinco e dez vezes a dose terapêutica, que demonstram sua estreita margem de segurança nesta espécie.

Palavras-chave: antiinflamatório, ciclooxigenase-2, toxicidade

\section{ABSTRACT}

This study investigated the margin of safety of the COX-2e inhibitor, meloxicam on blood cells and gastrointestinal tract of dogs. After a clinical and laboratorial examination, the dogs were distributed in the following groups: I (placebo; $n=3$ ), II (piroxicam: $1.0 \mathrm{mg} \mathrm{kg}^{-1} ; n=5$ ), III (meloxicam: $0.2 \mathrm{mg} \mathrm{kg}^{-1} ; n=5$ ),

${ }^{1}$ Aluna do Programa de Pós-graduação em Ciências Veterinárias; Professora de Cirurgia Veterinária, Faculdade de Veterinária (FV), Universidade Estadual do Ceará (UEC). Rua Pe. Leopoldo Fernandes, 573, Bairro de Fátima, 60411180, Fortaleza, CE. E-mail: marilacalencar@bol.com.br. Autor para correspondência.

${ }^{2}$ Professora Substituta de Patologia Veterinária, Departamento Medicina Veterinária, FV-UEC.

${ }^{3}$ Professora de Patologia Veterinária, Departamento Medicina Veterinária, FV-UEC.

${ }^{4}$ Professora de Patologia Veterinária, Departamento Medicina Veterinária, FV-UEC.

${ }^{5}$ Médica Veterinária, Laboratório de Patologia Clínica, FV-UEC.

${ }^{6}$ Alunos do Curso de Graduação, FV-UEC.

${ }^{7}$ Professor de Farmacologia Veterinária; Programa de Pós-graduação em Ciências Veterinárias; Departamento Medicina Veterinária , FV-UEC. 
IV (meloxican: $1.0 \mathrm{mg} \mathrm{kg}^{-1} ; \mathrm{n=5}$ ) and $V$ (meloxican: $2.0 \mathrm{mg} \mathrm{kg}$ $\left.{ }^{1} ; n=5\right)$. The drugs were given orally for 16 days. On the $17^{\text {th }}$ day the complete hemogram was repeated and the euthanasia and necropsy were then accomplished. In group I there were no significative alterations. In group II, all the dogs showed moderate episodes of vomit and diarrhea. The blood-cell profile was not modified. Two dogs had hematocrit and hemoglobin reduction. In the necropsy, hemorrhagic spots and moderate gastroduodenal lesions were seen. The microscopic analysis revealed the presence of gastritis and ulcerative enteritis. In group III, four dogs (80\%) showed vomit and diarrhea, without alteration in blood-cell profile. The microscopic analysis showed mild lesions in the gastric mucosa and hemorrhagic spots in the duodenum of four dogs. Histology showed lesions suggesting mild gastroenteritis. In group IV, all the dogs $(n=5)$ showed vomit and blood diarrhea. Four of them showed anemia ( $p \leq 0.05)$. Four and five dogs, respectively, had hematocrit and hemoglobin reduction. In addition, there was a significant ( $p \leq 0.05)$ leukocytosis, neutrophilia and linfopenia in $60 \%$ of the dogs. The necropsy showed hiperemia, hemorrhage and severe gastric ulcers in all the dogs. In the microscopic analyses, gastroenteritis ulcerative was present in all the animals. In group $V$, the dogs $(n=5)$ had serious vomit, diarrhea and melena episodes. The dogs that bore the treatment $(n=4)$ had anemia and leukocytosis with neutrophilia and linfopenia significatives $(p \leq 0.05)$. All the dogs had hematocrit and hemoglobin reduction. In the necropsy, hemorrhages and severe gastroduodenal ulceration were seen. The microscopic analysis showed severe gastroenteritis. It can be concluded that, although meloxicam is a COX-2 selective inhibitor, it induces deleterious effects on gastrointestinal tract and blood cells of dogs, when given five or ten times the therapeutic dose, which demonstrate its low margin of safety in this animal specie.

Key words: antiinflammatory, cyclooxygenase-2, toxicity

\section{INTRODUÇÃO}

Os fármacos antiinflamatórios nãoesteróides (DAINES) estão entre os mais utilizados de todos os agentes terapêuticos. Atualmente, há mais de cinqüenta diferentes DAINES no mercado e há, ainda, um fluxo contínuo de novas preparações. $\mathrm{O}$ grande número de novas substâncias significa que nenhuma dessas, até o momento, tem sido ideal no controle ou modificação dos sinais da inflamação, sem que haja efeitos deletérios no indivíduo (KORE, 1990; FORSYTH et al., 1998; BUDSBERG, 1999; BOOTHE, 2001).

A eficácia das DAINES decorre da inibição, específica ou não, da atividade das enzimas ciclooxigenases; fato este que resulta no bloqueio da gênese de prostaglandinas e tromboxanos (VANE, 1971; VANE \& BOTTING, 1995). Os mediadores próinflamatórios resultantes da ação da ciclooxigenase-1 (COX-1), que é a enzima constitutiva, estão representados pelas prostaglandinas relacionadas com os efeitos fisiológicos nos sistemas renal, gastrintestinal e cardiovascular (FROLICH, 1997; TASAKA, 1999; TANAKA et al., 2001). Por outro lado, a ciclooxigenase-2 (COX-2), enzima induzida, leva à formação de prostaglandinas presentes no processo inflamatório (VANE \& BOTTING, 1995; MARNET \& KALGUTKAR, 1999; KAY-MUGFORD et al., 2000). Dessa forma, as DAINES que bloqueiam inespecificamente as ciclooxigenases predispõem o surgimento de efeitos colaterais, especialmente relacionados com o trato gastrintestinal (BOOTHE, 2001).

Desde a década de 1990, vêm sendo introduzidas no mercado DAINES com maior especificidade para COX-2, como, por exemplo: meloxicam, carprofen, nimesulida, celocoxibe etc., que têm diminuído drasticamente a incidência de efeitos colaterais (JUSTUS \& QUIRKE, 1995; BUSCH et al., 1998; PAIRET et al., 1998; BUDSBERG, 1999; RAINSFORD et al., 1999; DOIG et al., 2000; MACPHAIL, 2000; MATHEWS et al., 2001). O meloxicam é um moderno derivado oxicano que desenvolve uma atividade inibitória seletiva sobre a COX-2 na cascata biossíntética das prostaglandinas. Em humanos, apresenta excelente tolerância, boa absorção digestiva e ótima biodisponibilidade; assim como longa meia vida de eliminação, o que permite sua administração em dose única diária (FROLICH, 1997). Contudo, são necessários estudos na medicina veterinária, que busquem determinar as particularidades farmacocinéticas e deletérias em cada espécie animal. Dessa forma, esta pesquisa teve como objetivo investigar a margem de segurança da conduta terapêutica com o meloxicam, em cães, enfocando seus efeitos deletérios nas células sangüíneas e no sistema gastrintestinal.

\section{MATERIAL E MÉTODOS}

Neste estudo, foram utilizados 23 cães adultos, sem raça definida, com peso variando entre 8 e $16 \mathrm{~kg}$, procedentes do canil da Prefeitura Municipal de Fortaleza. Os animais foram avaliados clínica e laboratorialmente antes da realização do protocolo experimental.

Após minucioso exame clínico, os animais que não apresentaram alterações foram considerados aptos para o experimento. Em seguida, o sangue $(5 \mathrm{ml})$ foi colhido e imediatamente remetido para realização do hemograma completo. Os cães que apresentaram alterações nos exames laboratoriais não entraram na pesquisa. Após esta triagem, os animais eram vermifugados por administração única da associação de pamoato de pirantel, pamoato de oxantel e praziquantel nas doses de $14,5,9,5$ e $2,5 \mathrm{mg} \mathrm{kg} \mathrm{PO}^{-1}$, respectivamente. Em seguida, permaneciam por um 
período de observação de 7 a 10 dias para que se iniciasse o protocolo experimental. Os grupos experimentais foram divididos da seguinte forma: Grupo $\mathrm{I}(\mathrm{n}=3)$ cães que receberam o placebo (água destilada; $2 \mathrm{ml}$ PO dia $\left.^{-1}\right)$; Grupo II ( $\left.\mathrm{n}=5\right)$, cães que receberam piroxicam na dose de $1 \mathrm{mg} \mathrm{kg} \mathrm{PO} \mathrm{dia}{ }^{-1}$; Grupo III $(\mathrm{n}=5)$, cães tratados com meloxicam na dose de $0,2 \mathrm{mg} \mathrm{kg} \mathrm{PO} \mathrm{dia}{ }^{-1}$; Grupo IV ( $n=5)$, cães tratados com meloxicam na dose de $1 \mathrm{mg} \mathrm{kg}$ PO dia ${ }^{-1}$ e Grupo V (n=5), cães que receberam meloxicam na dose de $2 \mathrm{mg} \mathrm{kg} \mathrm{PO} \mathrm{dia}{ }^{-1}$. Os Grupo I e II foram tomados como controles negativo e positivo, respectivamente. Os animais foram tratados durante 16 dias e, neste período, foram avaliados clinicamente todos os dias, sendo anotadas as alterações ocorridas durante cada tratamento. No décimo sétimo dia, foram realizadas coletas de sangue para os procedimentos dos exames laboratoriais (hemograma) e, em seguida, procedeu-se à eutanásia, de acordo com os padrões éticos da pesquisa científica, utilizando-se tiopental sódico na dose de $25 \mathrm{mg} \mathrm{kg}^{-1}$ por via intravenosa. Realizou-se, então, a necrópsia dirigida ao trato gastrintestinal e coletaram-se fragmentos de estômago e intestino, que foram acondicionados em formol a $10 \%$ para posterior realização de exames histopatológicos. Vale salientar que, durante o tratamento, os animais que vieram a óbito foram necropsiados, e os fragmentos dos órgãos de interesse, remetidos para o exame histopatológico.

A análise estatística foi realizada comparando-se o valor médio inicial do parâmetro avaliado versus o valor médio final dentro de cada grupo experimental, através do modelo GLM, empregando-se uma análise de variância univariável, seguida do teste LSD. Somente os valores de $\mathrm{p} \leq 0,05$ foram considerados significativos.

\section{RESULTADOS}

No grupo I (controle negativo), constituído pelos animais que receberam água destilada (placebo), não foram verificadas alterações clínicas, laboratoriais ou histopatológicas consideráveis.

No grupo tratado com piroxicam (Grupo II; controle positivo; $n=5)$, todos os cães apresentaram sinais gastrintestinais, tais como: vômito e fezes pastosas, que tiveram início, em média, do $4^{\circ}$ ao $9^{\circ}$ dia de tratamento. No tocante ao perfil celular sangüíneo, não houve alterações significativas no número de hemácias (Figura 1) (valor médio inicial: 6,3 x 106 vs. final: 5,2 × $10^{6}$ hemácias $\mathrm{mm}^{-3}$ ), nem de leucócitos (Figura 2) (valor médio inicial: $15,1 \times 10^{3}$ vs. final: $17,7 \times 10^{3}$ leucócitos $\left.\mathrm{mm}^{-3}\right)$. Observou-se que dois cães $(40 \%)$ tiveram uma redução significativa no hematócrito (valor médio inicial: 40,8 vs. final: $33,4 \%$ ) e na taxa de hemoglobina (valor médio inicial: $12,6 \mathrm{vs}$. final: $10,2 \mathrm{~g} \mathrm{dl}^{-1}$ ), respectivamente. No exame post mortem, 80 e $100 \%$ dos animais, respectivamente, apresentaram alterações gástricas e duodenais moderadas, do tipo: hemorragias e ulcerações. Os principais achados histopatológicos no estômago, de $80 \%$ dos cães, caracterizaram-se por: erosões, ulcerações, destruição do epitélio colunar das fossetas, infiltração leucocitária na lâmina própria, edema, espessamento da submucosa e dilatação vascular. No intestino delgado, por sua vez, observouse enterite ulcerativa, em todos os cães, caracterizada por: vilos em forma de dedo, destruição do epitélio de superfície, degeneração das criptas, erosão e necrose da camada mucosa, hiperplasia de glândulas da submucosa, degeneração e necrose da camada muscular, edema, congestão, aumento de células linfoplasmocitárias e infiltrado inflamatório.

No Grupo III $(\mathrm{n}=5)$, tratado com meloxicam $0,2 \mathrm{mg} \mathrm{kg}^{-1}, 80 \%$ dos cães apresentaram discretas alterações clínicas, como episódios de vômitos e fezes pastosas, a partir do $5^{\circ}$ dia de medicação. As alterações na série vermelha (Figura 1) (valor médio inicial: 5,8 x $10^{6}$ vs. final: $4,9 \times 10^{6}$ hemácias $\mathrm{mm}^{-3}$ ) e branca (Figura 2) (valor médio inicial: $14,6 \times 10^{3}$ vs. final: $15,0 \times 10^{3}$ leucócitos $\mathrm{mm}^{-3}$ ) não foram significativas. Na necropsia, observaram-se, em $80 \%$ dos animais, hiperemia e discretas erosões na mucosa gastroduodenal (Figura 3). Na histopatologia, conforme demonstrado na Figura 4 , observou-se um discreto processo de gastrite, em $60 \%$ dos animais, caracterizada por descamação epitelial, necrose do epitélio superficial, erosão e edema na camada mucosa, edema e congestão na submucosa, necrose de células principais e parietais e infiltrado inflamatório. Ademais, quatro cães tiveram discreta enterite linfoplasmocitária (Figura 4), com as seguintes alterações: vilos em forma de dedo, destruição do epitélio superficial, erosão na mucosa, edema na submucosa, congestão e infiltrado linfloplasmocitário na lâmina própria.

No Grupo IV ( $\mathrm{n}=5)$, tratado com meloxicam $1,0 \mathrm{mgkg}^{-1}$, todos os cães apresentaram sinais gastrintestinais, do tipo: vômito e diarréia sanguinolenta a partir do $4^{\circ}$ dia de tratamento. No tocante à série celular sangüínea, observaram-se, em 5 e 3 cães, respectivamente, anemia (Figura 1) (valor médio inicial: $5,8 \times 10^{6}$ vs. final: $4,9 \times 10^{6}$ hemácias $\left.\mathrm{mm}^{-3} ; \mathrm{p} \leq 0,05\right) \mathrm{e}$ leucocitose (Figura 2) (valor médio inicial: $13,0 \times 10^{3} \mathrm{vs}$. final: $34,1 \times 10^{3}$ leucócitos $\left.\mathrm{mm}^{-3} ; \mathrm{p} \leq 0,05\right)$ com neutrofilia (valor médio inicial: $8,3 \times 10^{3}$ vs. final: $24,5 \times 10^{3}$ neutrófilos $\mathrm{mm}^{-3} ; \mathrm{p} \leq 0,05$ ) e linfopenia relativa (valor médio inicial: $19,40 \%$ vs. final: $10,20 \%$; $\leq 0,05$ ). Ademais, observou-se que 80 e $100 \%$ dos cães

Ciência Rural, v. 33, n. 3, 2003. 


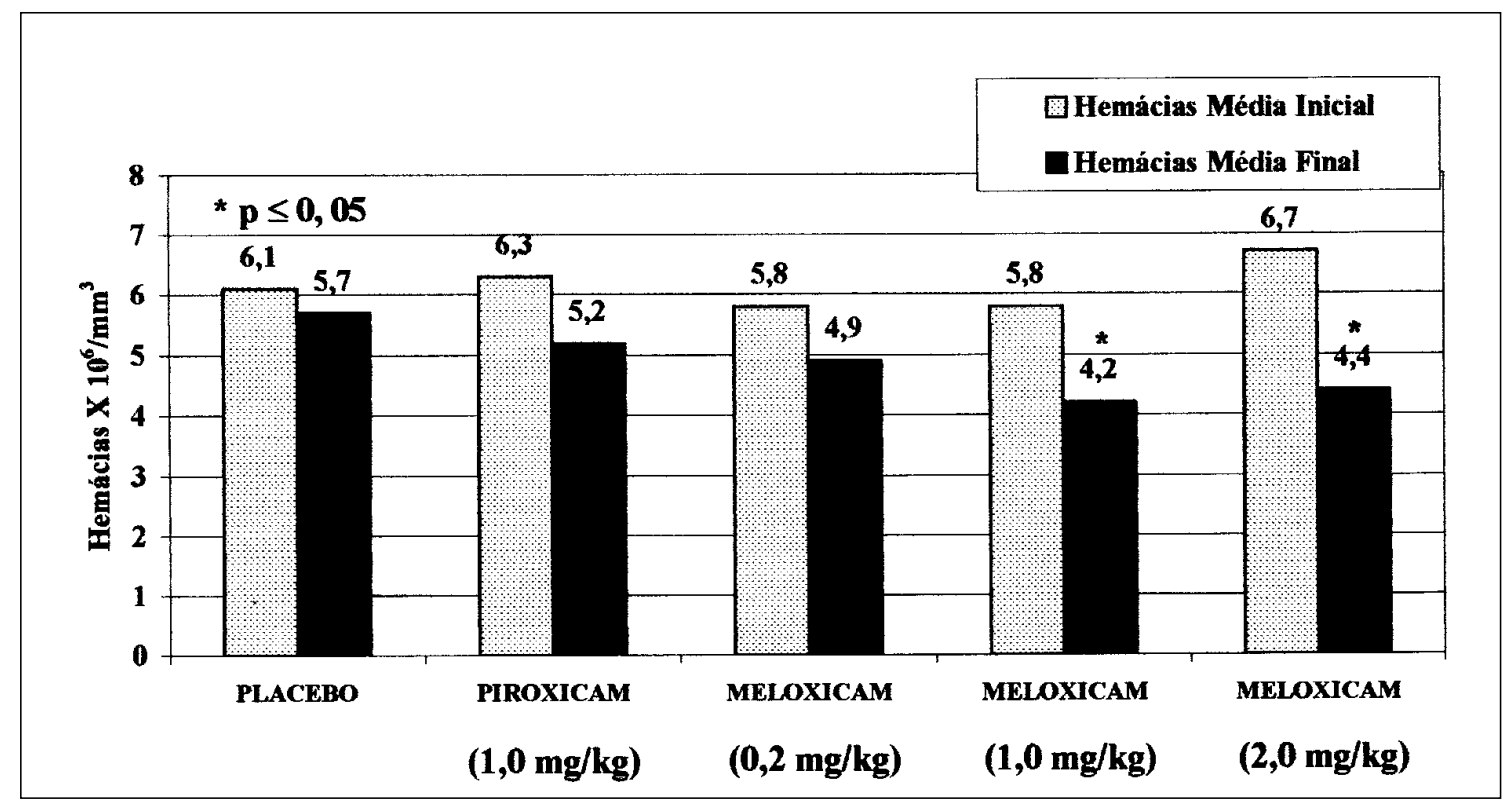

Figura 1 - Total de hemácias dos cães tratados com inibidores seletivos ou não da enzima ciclooxigenase. Esta figura evidencia que apenas o meloxicam $(1,0$ e $2,0 \mathrm{mg} / \mathrm{kg})$, inibidor COX-2 seletivo, é capaz de induzir significativa anemia. *p $\leq 0,05$; análise de variância, seguida do teste LSD, correspondente a comparação entre o valor médio inicial do número de hemácias versus o valor médio final de cada grupo experimental.

apresentaram redução $(\mathrm{p} \leq 0,05)$ no hematócrito (valor médio inicial: 38,2 vs. final: $27,8 \%$ ) e na taxa de hemoglobina (valor médio inicial: 12,48 vs. final: $8,16 \mathrm{~g} \mathrm{dl}^{-1}$ ), respectivamente. A necropsia evidenciou, em 100\% dos animais, hemorragias, hiperemia, escavações e úlceras gástricas profundas; bem como hiperemia e escavações na mucosa duodenal (Figura 3). Um cão apresentou perfuração gástrica, que foi ocluída pelo lobo hepático. Quanto à histopatologia, todos os animais tiveram gastrite ulcerativa moderada (Figura 4), caracterizada por destruição do epitélio superficial, congestão na submucosa, degeneração da camada muscular, atrofia glandular, edema, necrose e infiltrado inflamatório. A análise morfológica do duodeno revelou a presença de enterite hipertrófica (Figura 4), com destruição do epitélio superficial, degeneração das criptas, hiperplasia glandular na submucosa, espessamento da membrana basal, hipertrofia da camada muscular, infiltrado mononuclear linfoplasmocitário, edema, congestão e infiltrado inflamatório.

No grupo V, tratado com meloxicam 2,0mg/ $\mathrm{kg}(\mathrm{n}=5)$, todos os animais apresentaram sinais gastrintestinais severos, a partir do $4^{\circ}$ dia, caracterizado por vômitos profusos, diarréia e melena. Evidenciaramse, ainda, em 100\% dos cães, anemia (Figura 1) (valor médio inicial: $6,7 \times 10^{6} \mathrm{vs}$. final: 4,4 × $10^{6}$ hemácias $\mathrm{mm}^{-3}$; $\mathrm{p} \leq 0,05$ ), leucocitose (Figura 2) (valor médio inicial: $13,3 \times 10^{3}$ vs. final: $60,1 \times 10^{3}$ leucócitos $\mathrm{mm}^{-3} ; \mathrm{p} \leq 0,05$ ), neutrofilia (valor médio inicial: $8,0 \times 10^{3}$ vs. final: $43,0 \mathrm{x}$ $10^{3}$ neutrófilos $\mathrm{mm}^{-3} ; \mathrm{p} \leq 0,05$ ) e linfopenia relativa (valor médio inicial: $21,50 \%$ vs. final: $4,25 \%$; $\leq \leq 0,05$ ). Observou-se também que todos os cães tiveram uma redução $(\mathrm{p} \leq 0,05)$ no hematócrito (valor médio inicial: 43,0 vs. final: $31,5 \%$ ) e na hemoglobina (valor médio inicial: 14,02 vs. final: $9,07 \mathrm{~g} / \mathrm{dl}$ ). Na necropsia, todos os animais que chegaram ao final do tratamento $(n=4)$ apresentaram hemorragias profusas e úlceras gastroduodenais severas (Figura 3). Na avaliação histopatológica, os quatro cães apresentaram um grave processo de gastrite (Figura 4), sendo, em três deles, do tipo erosiva difusa e, em um, do tipo ulcerativa. As principais alterações microscópicas, encontradas no estômago, foram as seguintes: aprofundamento e separação das fossetas, submucosa com congestão, edema, necrose, erosão e ulceração, espessamento e infiltração leucocitária na camada serosa, degeneração da camada muscular, necrose de células parietais e principais, congestão na lâmina própria e infiltrado de células polimorfonucleares e mononucleares. No duodeno, por sua vez, observou-se uma enterite severa (Figura 4), caracterizada por: vilos chatos e em forma de dedos, necrose dos vilos, destruição do epitélio superficial, destruição e erosão da mucosa, distensão, 


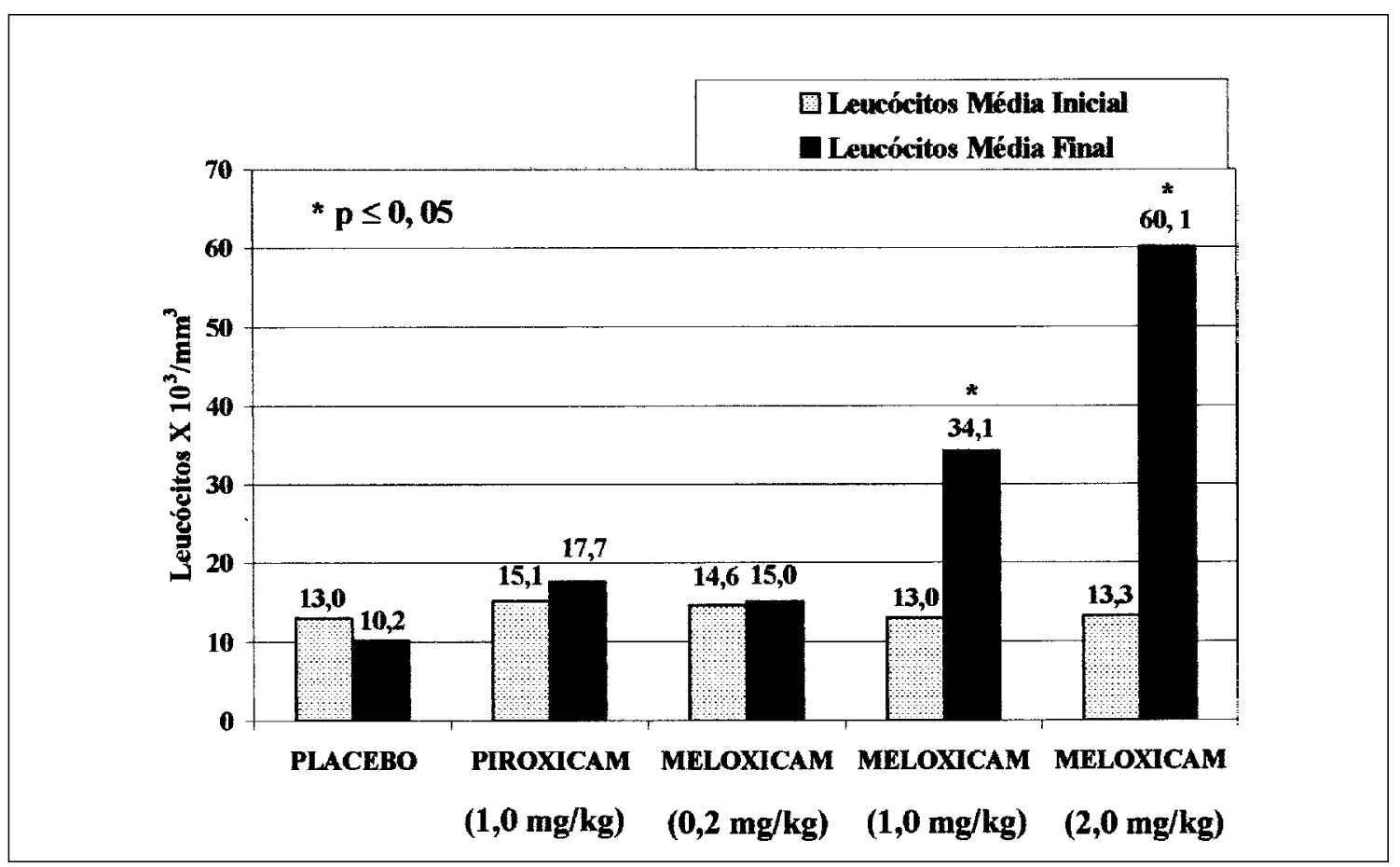

Figura 2 - Total de leucócitos dos cães tratados com inibidores seletivos ou não da enzima ciclooxigenase. Esta figura evidencia que apenas o meloxicam (1,0 e 2,0mg/kg), inibidor COX-2 seletivo, é capaz de induzir significativa leucocitose. *p $\leq 0,05$; análise de variância, seguida do teste LSD, correspondente a comparação entre o valor médio inicial do número de leucócitos versus o valor médio final de cada grupo experimental.

necrose, edema, degeneração hialina e hipertrofia glandular na camada submucosa, aumento de células caliciformes, acúmulos linfóides na lâmina própria e degeneração, necrose, infiltrado inflamatório e glicogenólise da camada muscular.

\section{DISCUSSÃO}

A terapia antiinflamatória teve uma evolução significativa a partir da descoberta do mecanismo de ação das drogas antiinflamatórias não-esteróides por John Vane em 1971. No final dos anos 80, com a descoberta da existência de duas isoformas de ciclooxigenase (COX-1 e COX-2), que determinam diferentes funções no organismo, os pesquisadores abriram novos horizontes para o estabelecimento de uma conduta terapêutica mais eficaz e com menor incidência de efeitos colaterais (BUSCH et al., 1998; RICKETTS et al., 1998; RAINSFORD et al., 1999; BUDSBERG, 1999; KAY-MUGFORD et al., 2000; DOIG et al., 2000; MATHEWS et al., 2001). Na medicina veterinária, em especial na clínica de pequenos animais, há uma carência de protocolos terapêuticos que padronizem o uso clínico de inibidores de COX-2. Dessa forma, a presente investigação foi conduzida no sentido de avaliar o uso do meloxicam, em cães, visando a determinar sua margem de segurança nesta espécie animal.

A margem de segurança de um determinado fármaco corresponde ao intervalo entre a dose terapêutica e a dose tóxica. Neste estudo, utilizou-se o meloxicam, inibidor COX-2 seletivo, em três diferentes dosagens a fim de testar a sua margem de segurança em cães. Dessa forma, foi usada a dose terapêutica $\left(0,2 \mathrm{mg} \mathrm{kg}^{-1} / \mathrm{PO} / \mathrm{dia}\right)$, preconizada por VAN BREE et al. (1994) e testadas concentrações cinco e dez vezes superiores. Nesta investigação, o piroxicam, inibidor inespecífico de COX foi usado como controle positivo, pois nesta dosagem é capaz de produzir severas alterações nos sistemas gastrintestinal e renal (BOOTHE, 2001). O grupo controle negativo (placebo) foi representado pelo grupo que recebeu apenas água por via oral.

Os dados apresentados nesta investigação apontam uma estreita margem de segurança do meloxicam em cães, haja vista que, mesmo na dosagem recomendada, apareceram sinais relacionados com o trato gastrintestinal, ou seja, $80 \%$ dos cães 

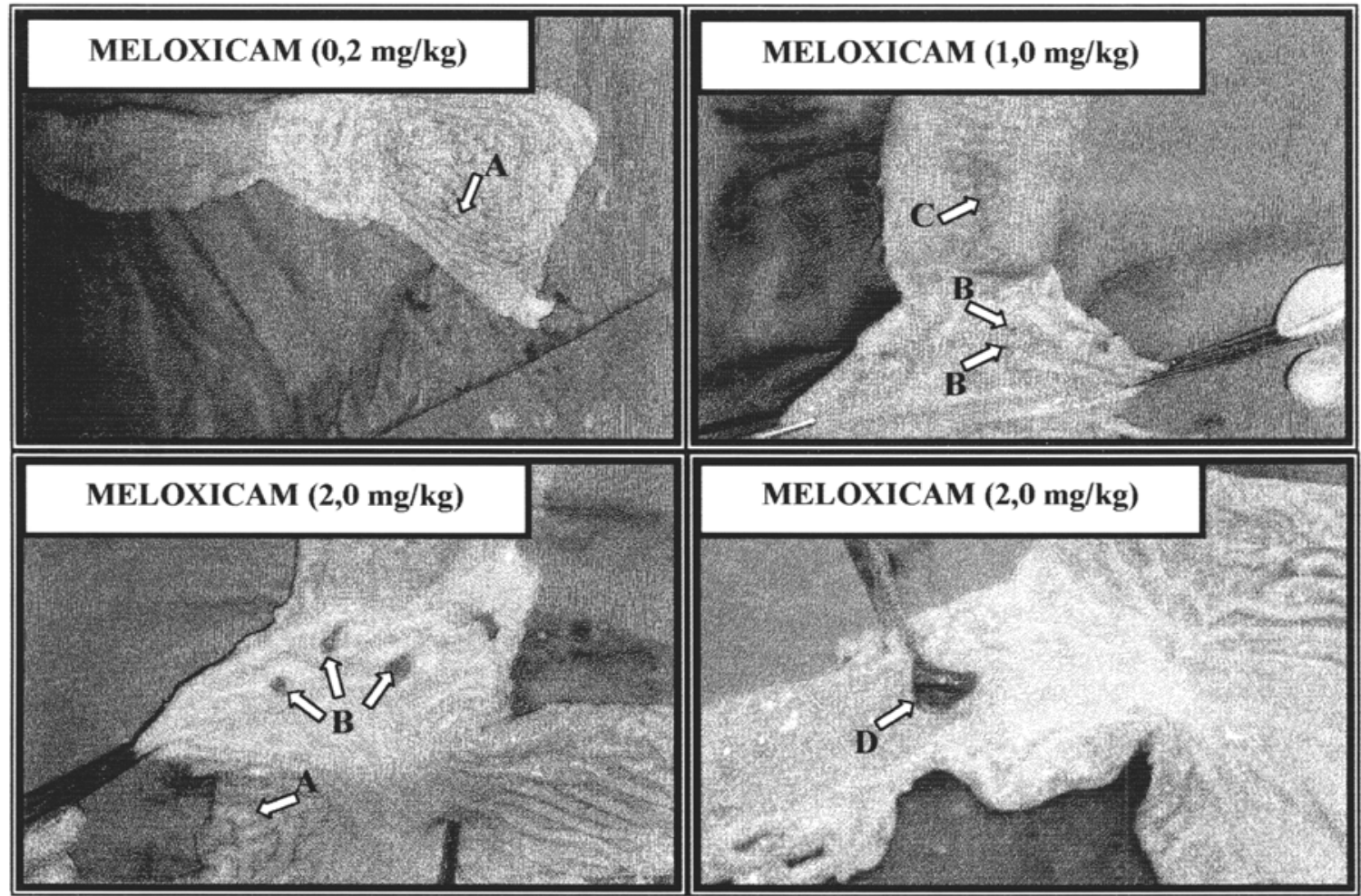

Figura 3 - Alterações macroscópicas no trato gastrintestinal de cães tratados com meloxicam. Esta figura evidencia que a severidade das alterações gastrintestinais, tais como: hiperemia (A), ulcerações (B), enterite (C) e perfuração (D), provocadas pelo uso do meloxicam ocorre de maneira dose-dependente.

apresentaram episódios de vômitos e fezes pastosas, que sugerem uma possível atividade deletéria neste sistema. Corroborando esta evidência, tem sido relatado que as DAINES, mesmo em doses terapêuticas, podem causar lesão na mucosa gastrintestinal, predispondo o surgimento de emese, hemorragias intestinais ocultas e quadros diarréicos (BOOTHE, 2001). Ademais, LEICONDRE (1999) refere que as úlceras resultantes de terapia antiinflamatória, observadas por endoscopia, encontram-se especialmente na região antro-pilórica, sob a forma de erosões múltiplas com pontos hemorrágicos adjacentes. Estando estas evidências, portanto, em acordo com os resultados desta investigação com meloxicam.

É importante ressaltar que o meloxicam (1,0 e 2,0 $\left.\mathrm{mg} \mathrm{kg}^{-1}\right)$ induziu efeitos deletérios no trato digestivo dos cães, caracterizados por inapetência, vômitos profusos, diarréia sanguinolenta e lesões gastroduodenais, que foram mais severos, até mesmo, que aqueles observados com o piroxicam. Dessa forma, comparando-se os resultados do meloxicam $\left(1,0 \mathrm{mg} \mathrm{kg}^{-1}\right)$ com aqueles do piroxicam, observou-se que o piroxicam, apesar de ser inibidor inespecífico de COX, foi menos agressivo na indução de emese, diarréia e lesões gastrintestinais. Vale salientar que o meloxicam $\left(2,0 \mathrm{mg} \mathrm{kg}^{-1}\right)$ provocou ulcerações gastrintestinais múltiplas, ocasionando óbito em um cão, por peritonite secundária à perfuração digestiva. Portanto, estes resultados sugerem que a incidência dos sinais e a severidade das lesões gastrintestinais, provocadas pelo uso do meloxicam, ocorrem de forma dose dependente, podendo, até mesmo, levar o animal a óbito.

Contrapondo-se aos dados encontrados nesta pesquisa, ANDRADE et al. (2001) não evidenciaram alterações clínicas nem macro e microscópicas significativas, relacionadas com o sistema gastrintestinal de cães tratados com meloxicam $\left(0,2 \mathrm{mg} \mathrm{kg}^{-1}\right)$. Entretanto, as evidências dos efeitos deletérios deste fármaco sobre o trato gastrintestinal, observados na presente investigação, podem ser ratificadas por um estudo realizado por RICKETTS et al. (1998), que demonstraram que o meloxicam, em linhagem celular de histiocitoma canino (DH82), in vitro, apresenta apenas uma discreta seletividade para a enzima COX-2. Por conseguinte, este achado laboratorial pode explicar, pelo menos em parte, os 


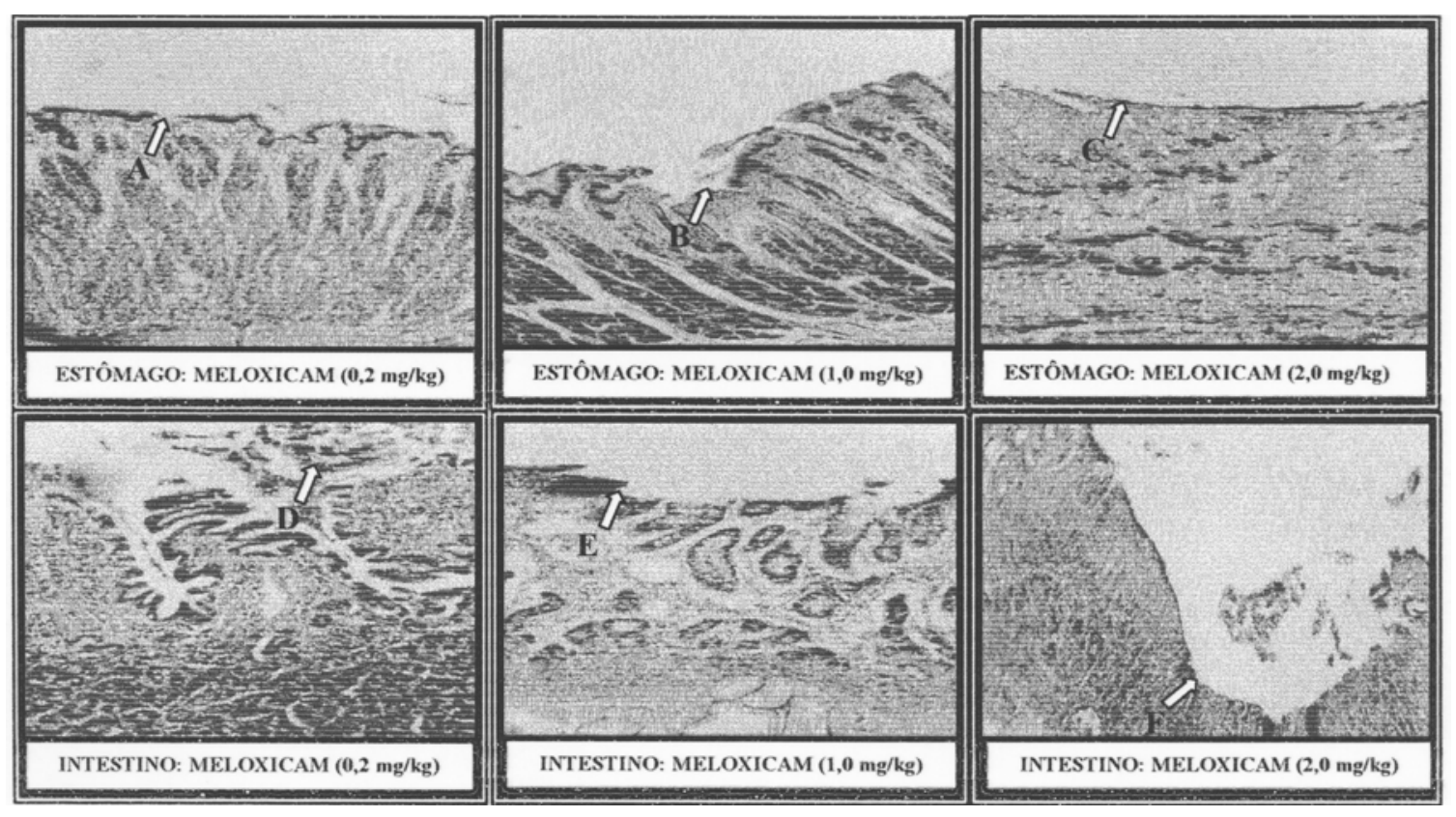

Figura 4 - Alterações microscópicas no trato gastrintestinal de cães tratados com meloxicam. No grupo que recebeu a dose preconizada para uso clínico $(0,2 \mathrm{mg} / \mathrm{kg})$, observa-se apenas discreta descamação epitelial no estômago (A). As doses de 1,0 e $2,0 \mathrm{mg} / \mathrm{kg}$ induziram, respectivamente, ulcerações gástricas moderadas (B) e graves (C). No intestino, podem ser observadas descamação epitelial (D), erosão (E) e severa ulceração $(\mathrm{F})$, nos grupos tratados com meloxicam $0,2,1,0$ e 2,0mg/kg, respectivamente. Coloração: HE; Aumento: $100 \mathrm{x}$.

efeitos indesejados do meloxicam no trato digestivo de cães, in vivo, aqui relatados. Em adição, FORSYTH et al. (1998) observaram a presença de lesões gastrintestinais em cães tratados com meloxicam $\left(0,2 \mathrm{mg} \mathrm{kg}^{-1}\right)$.

Os efeitos deletérios das DAINES, no trato gastrintestinal, resultam tanto de uma irritação local, como da inibição da biossíntese de $\mathrm{PGI}_{2}$ e $\mathrm{PGE}_{2}$ que, por sua vez, controlam a secreção de $\mathrm{HCl}$, promovem a secreção de muco citoprotetor, aumentam a secreção de bicarbonato, aumentam o fluxo sangüíneo e mantêm a integridade endotelial (TASAKA, 1999; BOOTHE, 2001). Nessa perspectiva, como o meloxicam em cães apresenta apenas discreta seletividade para a enzima COX-2, conforme observado por RICKETTS et al. (1998), a síntese de $\mathrm{PGI}_{2}$ e $\mathrm{PGE}_{2}$, muito provavelmente, é bloqueada por este fármaco, predispondo uma diminuição na citoproteção gástrica e, por conseguinte, o surgimento de alterações gastrintestinais.

No tocante ao padrão celular sangüíneo, o protocolo terapêutico do meloxicam $\left(0,2 \mathrm{mg} \mathrm{kg}^{-1}\right)$ não alterou de modo significativo as séries branca e vermelha, uma vez que os valores obtidos no leucograma ficaram dentro dos padrões da normalidade para a espécie, conforme os preconizados por SILVEIRA (1988). Contudo, os cães que receberam meloxicam $\left(1,0 \mathrm{mg} \mathrm{kg}^{-1}\right)$ apresentaram alterações em ambas as séries, caracterizadas por anemia, leucocitose, neutrofilia e linfopenia. Houve, ainda, redução no hematócrito e na taxa de hemoglobina. O meloxicam $\left(2,0 \mathrm{mg} \mathrm{kg}^{-1}\right)$, por sua vez, produziu estas alterações hematológicas em $100 \%$ dos cães e com um grau de severidade bem mais acentuado, demonstrando, portanto, que esse fármaco induz alterações no perfil celular sangüíneo de forma dose dependente.

O valor médio final do número de hemácias nos grupos meloxicam (1,0 e 2,0 $\left.\mathrm{mg} \mathrm{kg}^{-1}\right)$ ficou abaixo dos demais tratamentos. Este fato pode ser explicado pelos achados laboratoriais de insuficiência renal (dado não mostrado), visto que, nesta patologia, o rim fica incapacitado de liberar quantidades adequadas de eritropoetina. Em adição, anemia, secundária à irritação, e ulceração gástrica são achados freqüentes em cães tratados com DAINES (BOOTHE, 2001). Quanto ao aumento no número de leucócitos, tem sido referido que um quadro de leucocitose com neutrofilia, com desvio à esquerda, pode ocorrer diante de infecções, inflamação imunomediada, necrose tissular e severa hemólise (SILVEIRA, 1988). Dessa forma, como as lesões gástricas e duodenais nos grupos meloxicam (1,0 e 2,0mg kg-1) foram bem mais extensas que nos demais grupos, fica justificada a razão da maior 
intensidade das alterações no padrão celular sangüíneo, observadas nos cães tratados com o meloxicam nestas concentrações.

Os dados desta pesquisa sugerem que o meloxicam, a exemplo do observado, in vitro, não apresenta substancial seletividade para a enzima COX-2, em cães, in vivo, uma vez que produz efeitos deletérios, dose-dependentes, no trato gastrintestinal e série celular sangüínea. Portanto, como esse fármaco mostrou uma estreita margem de segurança em cães, sua dose terapêutica deve ser respeitada na íntegra, sob sérios riscos de aparecimento de efeitos deletérios graves, que podem ser fatais.

\section{REFERÊNCIAS BIBLIOGRÁFICAS}

ANDRADE, S.F. et al. Estudo clínico e histopatológico do uso de antiinflamatório inibidor seletivo COX-2 (meloxicam) em cães. A Hora Vet, v.120, p.44-46, 2001.

BOOTHE, D.M. Anti-inflammatory drugs. In: BOOTHE, D.M. Small animal clinical pharmacology and therapeutics. Philadelphia : Saunders, 2001. Cap. 16, p.281-311.

BUDSBERG, S.C. Tendencias actuales y futuras en el uso de los AINEs para el tratamiento de la osteoartritis en los perros. Waltham Focus, v.9, p.26-31, 1999.

BUSCH, U. et al. Kinetics of meloxicam in animals and the relevance to humans. Drug Metab Dispos, v.26, p.576-584, 1998.

DOIG, P.A. et al. Clinical efficacy and tolerance of meloxicam in dogs with chronic osteoarthritis. Can Vet J, v.41, p.296300,2000 .

FORSYTH, S. F. et al. Endoscocopy of the gastroduodenal mucosa after carprofen, meloxicam and ketoprofen administration in dogs. J Small Anim Pract, v.39, p.421424, 1998.

FROLICH, J.C. A classification of NSAIDs according to the relative inhibition of cyclooxygenase isoenzymes. TIPS, v.18, p.30-34, 1997.

JUSTUS, C.; QUIRKE, J.F. Dose-response relationship for antipyretic effect of meloxicam in an endotoxin model in cats. Vet Res Commun, v.19, p.312-330, 1995.

KAY-MUGFORD, P. et al. In vitro effects of nonsteroidal anti-inflammatory drugs on cyclooxygenase activity in dogs. Am J Vet Res, v.61, p.802-810, 2000.
KORE, A.M. Toxicology of nonsteroidal anti-inflammatory drugs. Vet Clin North Am: Small Anim Pract, v.20, p.419430, 1990 .

LEICONDRE, P. Atlas de endoscopia gastrointestinal en perros y gatos. Walthan Focus, v.9, p.2-9, 1999.

MACPHAIL, C.M. Tratamiento de la osteoartritis canina. Waltham Focus, v.10, p.25-31, 2000.

MARNETT, L.J.; KALGUTKAR, A.S. Cyclooxygenase 2 inhibitors: discovery, selectivity and the future. TIPS, v.20, p.465-469, 1999.

MATHEWS, K.A. et al. Safety and efficacy of preoperative administration of meloxicam, compared with that of ketoprofen and butorphanol in dogs undergoing abdominal surgery. Am J Vet Res, v.62, p.882-888, 2001 .

PAIRET, M. et al. Differential inhibition of cyclooxygenases 1 and 2 by meloxican and its 4'-isomer. Inflamm Res, v.47, p.270-276, 1998.

RAINSFORD, K.D. et al. Effects of the NSAIDs meloxicam and indomethacin on cartilage proteoglycan synthesis and joint responses to calcium pyrophosphate crystals in dogs. Vet Res Commun, v.23, p.101-113, 1999.

RICKETTS, A.P.; LUNDY, K.M.; SEIBEL, S.B. Evaluation of selective inhibition of canine cyclooxygenase 1 and 2 by carprofen and other nonsteroidal anti-inflammatory drugs. Am J Vet Res, v.59, p.1441-1446, 1998.

SILVEIRA, J.M. Bioquímica clínica. In: Patologia clínica veterinária: teoria e interpretação. Rio de Janeiro : Guanabara, 1988. Cap. 5. p.86-97.

TANAKA, A. et al. Inhibition of both COX-1 and COX-2 is required for development of gastric damage in response to nosteroidal anti-inflammatory drugs. J Physiol Paris, v.95, p. $21-27,2001$.

TASAKA, A.C. Antiinflamatórios não-esteroidais. IN: SPINOSA, H.S.; GORNIAK, S.L.; BERNARDI, M.M. Farmacologia aplicada à medicina veterinária. 2 . ed. Rio de Janeiro : Guanabara Koogan, 1999. Cap. 21. p. 212226.

VAN BREE, H.; JUSTUS, C.; QUIRKE, J.F. Preliminary observations on the effects of meloxicam in a new model for acute intra-articular inflammation in dogs. Vet Res Commun, v. 18, p. $217-224,1994$.

VANE, J.R. Inhibition of prostaglandin synthesis as a mechanism of action for aspirin-like drugs. Nature, v.231, p.232-235, 1971.

VANE, J.R.; BOTTING, R.M. New insights into the model of action of anti-inflammatory drugs. Inflamm Res, v.44, p.110, 1995. 